\title{
Erratum to: Stress response signaling and virulence: insights from entomopathogenic fungi
}

\author{
Almudena Ortiz-Urquiza ${ }^{1} \cdot$ Nemat O. Keyhani $^{1}$
}

Published online: 3 April 2015

(C) Springer-Verlag Berlin Heidelberg 2015

\section{Erratum to: Curr Genet \\ DOI 10.1007/s00294-014-0439-9}

The original publication of the article unfortunately contained an error in one of the labelled circles which incorrectly indicates "Ssk1" instead of "Ssk2" in Fig. 3. The correct figure is given below:
Fig. 3 The core MAP kinase and cAMP/PKA pathways examined in entomopathogenic fungi. Protein products highlighted in red glow indicate corresponding genes that have been examined in either Beauveria and/or Metarhizium via targeted gene knockout

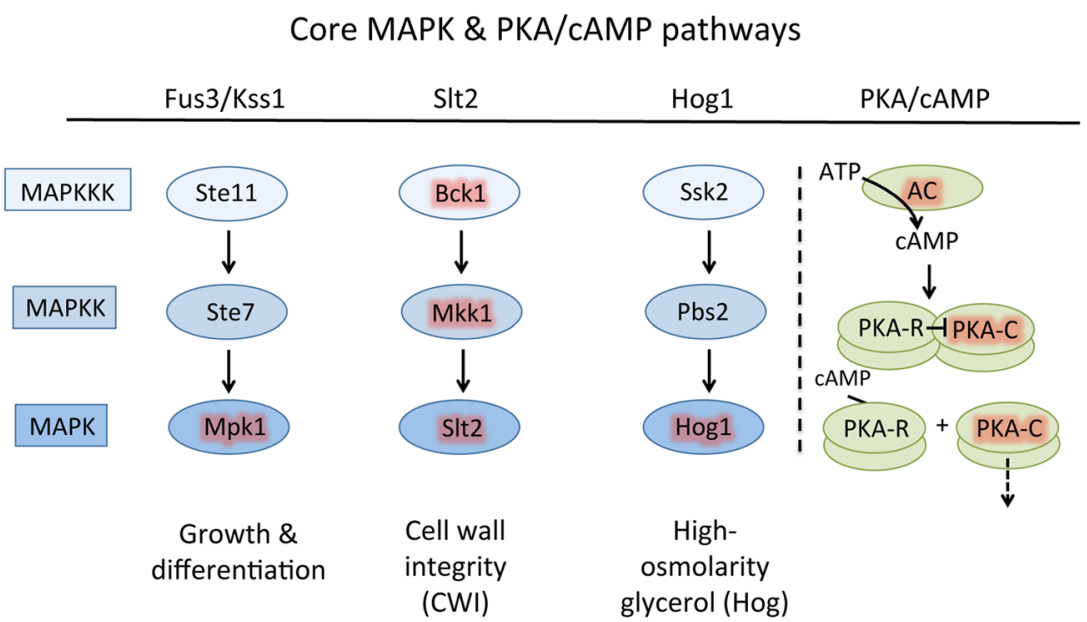

The online version of the original article can be found under doi:10.1007/s00294-014-0439-9.

Almudena Ortiz-Urquiza

almudenaortiz@ufl.edu

Nemat O. Keyhani

keyhani@ufl.edu

1 Department of Microbiology and Cell Science, University

of Florida, Gainesville, FL 32611, USA 